\title{
Awareness on Phytosanitary Measures for Pest Control in Timber Processing and Handling
}

\author{
Samuel Olalekan Olajuyigbe*, Maria Temiloluwa Oloyede \\ Email address: \\ lekito2001@yahoo.com (S. O. Olajuyigbe),marytemmy3@gmail.com (M. T. Oloyede) \\ ${ }^{*}$ Corresponding author
}

Department of Forest Production and Products, Faculty of Renewable Natural Resources, University of Ibadan, Ibadan, Nigeria

To cite this article:

Samuel Olalekan Olajuyigbe, Maria Temiloluwa Oloyede. Awareness on Phytosanitary Measures for Pest Control in Timber Processing and Handling. American Journal of Agriculture and Forestry. Vol. 5, No. 5, 2017, pp. 150-156. doi: 10.11648/j.ajaf.20170505.13

Received: August 22, 2017; Accepted: September 6, 2017; Published: September 26, 2017

\begin{abstract}
Phytosanitary measures are management techniques used to prevent unintentional movement of insect pests during timber processing and handling. In this study, the level of awareness on phytosanitary measures used for insect pest control during timber harvesting and post harvesting operations were assessed in Osun, Oyo and Lagos states in Nigeria. Questionnaires (331) were administered to plank marketers, saw mill workers, plant quarantine service workers, forestry officials and tree loggers in the three states. Information on knowledge about phytosanitary measures, pest control and perceptions towards pest infestation was elicited. Data were analysed using descriptive statistics, chi square, and logit regression analysis. The respondents $(80.0 \%)$ noticed pest infestation in their timber/planks before selling and $93.3 \%$ claimed that there were no regulatory bodies in charge of pest management in the forestry sector. The plank marketers used chemical $(34.2 \%)$ and biological treatments $(0.8 \%)$ for pest control while saw mill workers used chemical method $(42.3 \%)$ and painting (4.9\%). Logit regression analysis showed that awareness on phytosanitary measures had a positive impact on the willingness of the respondents to adopt the use of phytosanitary measures with an odd ratio of 13.50. Insect pest infestation resulted in reduced income and poor quality timber products. There is, therefore, a need for concerted efforts to generate interest in insect pest control using phytosanitary measures.
\end{abstract}

Keywords: Integrated Pest Management, Timber Processor, International Standard Phytosanitary Measures, Wood Preservation

\section{Introduction}

Healthy forests are vital to the healthy state of ecosystems because they are capable of self-renewal; resilient in their response to natural and artificial disturbances (pests, fire, and human-caused disturbances). Thus, forests are able to sustain the integrity of natural and cultural benefits $[1,2]$. Insect pests live in and on trees, consuming their leaves, bark, wood and roots for food, protection and shelter. Forest products thus contain insects which become pests when their populations exceed economic injury levels. These small invertebrate herbivores are capable of damaging forest trees while constituting a major source of loss of wood products [3, 4].

Insect pests cause damages to trees in all stages of their development and affect the ability of both natural forests and plantations to meet forest management objectives [5]. There is a large variety of insects that attack timber during various stages of its utilization, starting from tree felling in the forest, up to the stages of processing and utilization [6]. Consequently, forest managers need to be aware of the potential impacts that these pests might have on the quantity and quality of benefits derivable from forests [7].

Phytosanitary measures are legislative and official actions pertaining to plant quarantine, which are used during timber harvesting and post-harvesting operations in order to prevent the movement of pests or invasive species from one place to another. These measures and regulations serve as preventative management techniques aimed at forestalling unintentional movement of all kinds of insect pests. Unfortunately, in many tropical countries, low level of 
awareness of phytosanitary measures among plank marketers, tree loggers and saw millers limit the growth and development of the timber industry. In most cases, these phytosanitary measures are not in place during timber harvesting and post harvesting operations, resulting in pest infestation and inoculation, loss of aesthetic value and subsequent loss of income. It also limits the ability of the industry to produce certified timber products and access international markets $[1,4]$.

Pests can have detrimental effects on the durability and appearance of timber; causing aesthetic and structural damages as well as economic loss. Insect pests which attack trees and fresh logs usually bore into the inner bark and live there for a variable period of time, before they eventually penetrate the wood $[8,9]$. Knowledge and implementation of phytosanitary measures in timber harvesting and processing will improve handling procedures and enhance sustainable management of the renewable resource. It would also reduce the incidence of pest and disease outbreaks within the forests [4]. Therefore, this study determined the level of awareness on the use of phytosanitary measures during timber harvesting and post harvesting operations among tree loggers, saw millers and forestry officials in southwest Nigeria.

\section{Materials and Methods}

This study was carried out in Osun, Oyo, and Lagos states of Nigeria. Five saw mills containing timber markets were purposively selected: Orisunbare and Isokan saw mills (in Ikoyi and Ikire, Osun State); Alomaja and Temidire saw mills (in Ibadan, Oyo state) and Oko Oba saw mill (in EbuteMetta, Lagos State) (Figure 1). Three hundred and thirty-one structured questionnaires (Table 1) were administered to: forestry officials (43), plant quarantine officers (10), tree fellers (35), saw mill workers (123) and plank marketers (120). The plant quarantine officers were interviewed at the National Agricultural Quarantine Centre, Ibadan, Nigeria, while forestry officials were sourced from the Department of Forestry in each state.

The questionnaires were used to elicit information on the level of awareness on the use of phytosanitary measures during timber harvesting and processing, the effect of pest infestation on the value of forest products and the methods used for controlling insect pests. The qualitative data were analysed using descriptive statistics, chi-square, and logit regression analysis.

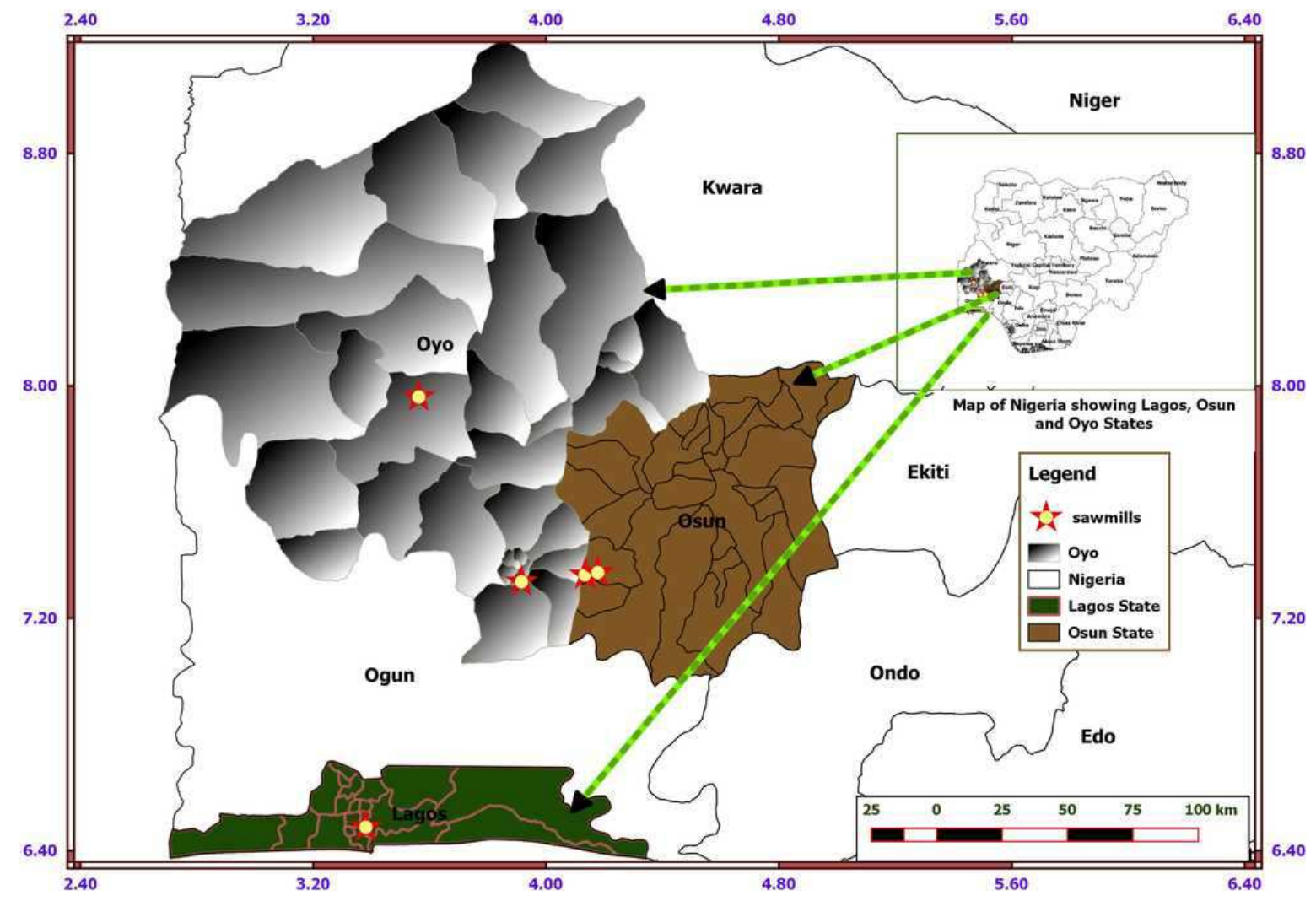

Figure 1. Map showing location of selected saw mills in Osun, Oyo and Lagos states, southwest Nigeria.

Table 1. Number of respondents interviewed in the selected saw mills in Osun, Oyo and Lagos states, south west Nigeria.

\begin{tabular}{llllllll}
\hline State & Description & Plant quarantine officers & Forestry officials & Tree loggers & Saw mill workers & Plank marketers & Total \\
\hline Osun & Ikoyi and Ikire & - & 17 & 5 & 50 & 20 & 92 \\
Oyo & Ibadan & 10 & 19 & 30 & 23 & 50 & 132 \\
Lagos & Ebute-Metta & - & 07 & - & 50 & 50 & 107 \\
Total & 4 & 10 & 43 & 35 & 123 & 120 & 331 \\
\hline
\end{tabular}




\section{Results}

\subsection{Knowledge of Phytosanitary Measures}

The forest managers and plant quarantine officers had little training in pest identification with $83 \%$ of the respondents lacking basic knowledge on insect ecology. In the plank markets, $21.7 \%$ of the respondents admitted that the pests had a negative effect on the sale of wood products while an alarming $77.5 \%$ sold infested planks without any form of treatment. In saw mills, $74.8 \%$ had insect pest occurrences, while $79.7 \%$ of saw mill workers checked the physical status of their logs before sawing. One-third of the plank marketers had heard about phytosanitary measures. These plank marketers obtained information about phytosanitary measures from forestry officials $(4.2 \%)$, through Integrated Pest Management training (0.8\%), from Agricultural Extension Agents (3.3\%) and through other means (26.3\%). On the contrary, most of the saw mill workers $(81.3 \%)$ had no knowledge of phytosanitary measures with $12.2 \%$ of them obtaining information from forestry officials, while $0.8 \%$ claimed to get information about pest management from their colleagues. It was discovered that a high proportion of respondents $(84.6 \%)$ had not heard about phytosanitary measures.

\subsection{Sources of Information on Phyto-Sanitation}

Forestry officials and plant quarantine officers (41.5\%) had adequate knowledge of phytosanitary measures used in timber processing and handling. These groups of respondents sourced their information from the National Plant Protection Organizations (24.5\%), International Plant Protection Convention (5.7\%), Integrated Pest Management protocols (5.7\%), and experienced colleagues (5.7\%) (Figure 2). Nonetheless, a large percentage of them confirmed that the measures were not being used (Figure 3). For plank marketers, the location, gender, and educational background had significant effects on the level of awareness about phytosanitary measures (Table 2). The logit regression revealed that only the phytosanitary awareness and pest information records influenced the willingness to use such methods for insect pest management and control (Table 3).

Table 2. Influence of selected variables on the level of awareness of phytosanitary measures in plank markets, saw mills and among tree loggers.

\begin{tabular}{llllll}
\hline \multirow{2}{*}{ Variable } & Plank markets & & Saw mill & \multicolumn{2}{c}{ Tree loggers } \\
\cline { 2 - 6 } & Chi square value & P value & Chi square value & P value & Chi square value \\
\hline Location & 25.48 & $0.000^{*}$ & 0.303 & $0.859 \mathrm{~ns}$ & 0.303 \\
Gender & 10.57 & $0.001^{*}$ & 0.368 & $0.544 \mathrm{~ns}$ & 0.368 \\
Marital Status & 0.005 & $0.945 \mathrm{~ns}$ & 2.149 & $0.143 \mathrm{~ns}$ & 2.149 \\
Education & 30.68 & $0.000^{*}$ & 8.997 & $0.061 \mathrm{~ns}$ & 8.997 \\
Experience & 5.18 & $0.159 \mathrm{~ns}$ & 2.278 & $0.685 \mathrm{~ns}$ & 2.278 \\
\hline
\end{tabular}

$\mathrm{ns}=$ not significant, $*=$ significant at $\mathrm{p}<0.05$

Table 3. Logit regression on willingness of the respondents to use phytosanitary measures during timber harvesting, processing and handling.

\begin{tabular}{llll}
\hline Independent Variable & Coefficient model & Odds-ratio & P value \\
\hline Gender & 0.365 & 1.44 & $0.511 \mathrm{~ns}$ \\
Marital status & 0.406 & 1.5 & $0.596 \mathrm{~ns}$ \\
Pest Infestation Record & -1.294 & 0.273 & $0.024 *$ \\
Phytosanitary Measures Awareness & 2.603 & 13.50 & $0.000^{*}$ \\
Age & -0.018 & 0.981 & $0.450 \mathrm{~ns}$ \\
\hline
\end{tabular}

Final Loss $=55.281 ;$ Chi Square value $=26.918 ; \mathrm{df}=5 ; \mathrm{p}=0.00006$

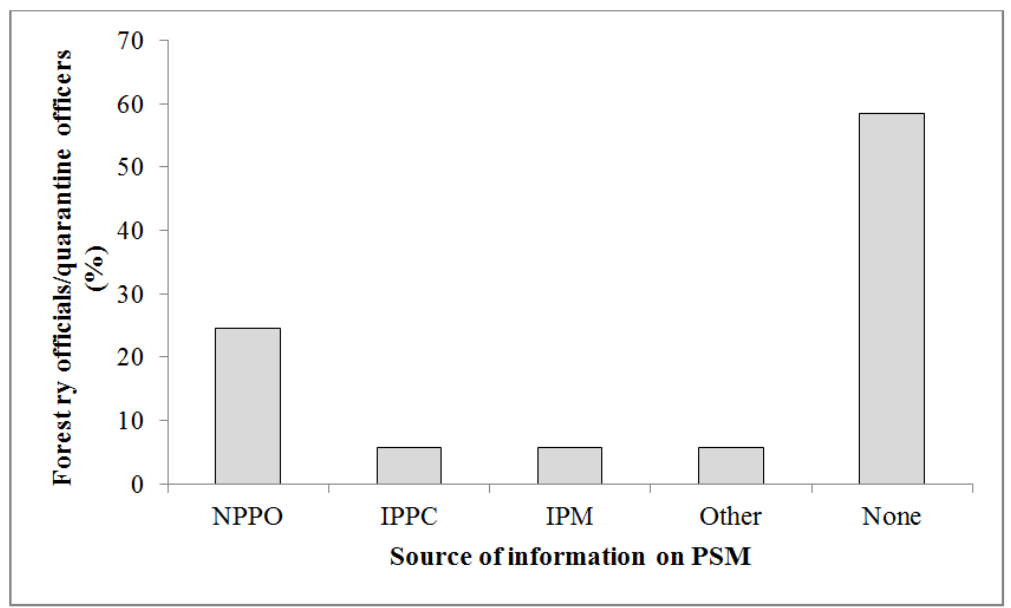

Figure 2. Sources of information on international phytosanitary measures (PSM) recommended for timber harvesting, processing and handling (NPPO: National Plant Protection Organization, IPPC: International Plant Protection Convention, IPM: Integrated Pest Management). 


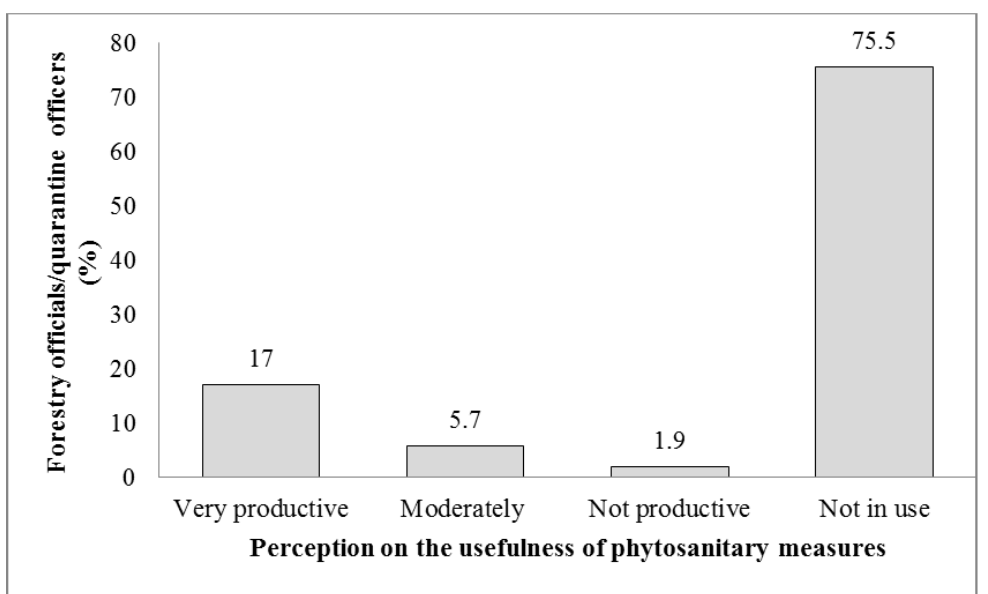

Figure 3. Perception of forestry officials and plant quarantine officers on the usefulness of phytosanitary measures in timber harvesting, processing and handling.

\subsection{Insect Pest Infestations}

Although $80.8 \%$ of the timber processors and handlers had noticed pest infestations on their timber/planks before selling, $93.3 \%$ claimed that there was no regulatory body in charge of pest management in the forestry industry in southwest Nigeria. However, $4.2 \%$ had reported previous pest infestations to government agencies and requested for assistance. Nonetheless, most of the timber processors perceived that insect pest infestations had little negative impact on the value of their products, with all tree loggers suggesting that there was no negative effect (Figure 4). Consequently, a larger proportion of the respondents continued the sale of infested timber products (Figure 5). Ironically, the majority of the respondents agreed that insect pests reduced their accruable income (Figure 6). During the survey, two coleopterans (Bostrychoplites cornutus and Alaus excavates) were commonly observed in all saw mills.

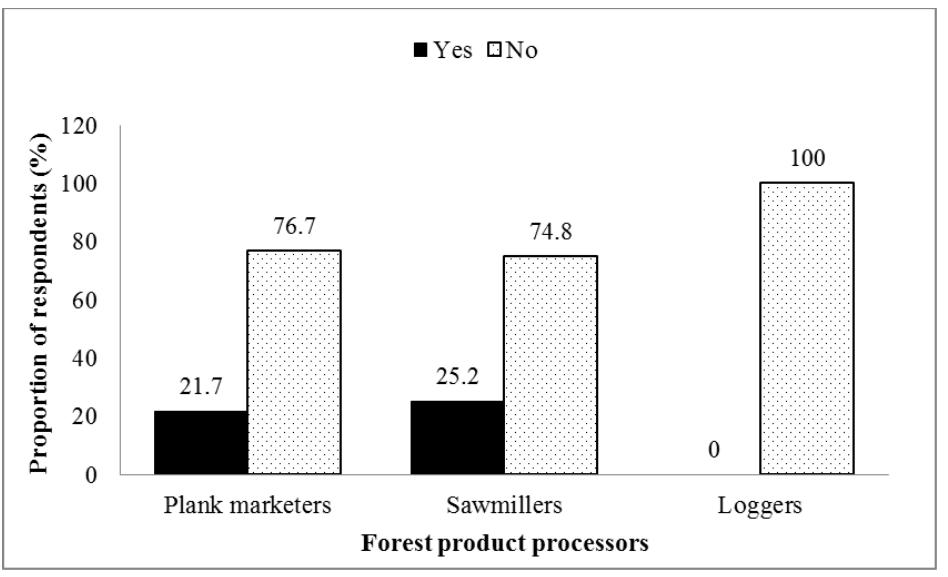

Figure 4. Perception of timber product processors on the effect of insect pests on the economic value of timber products.

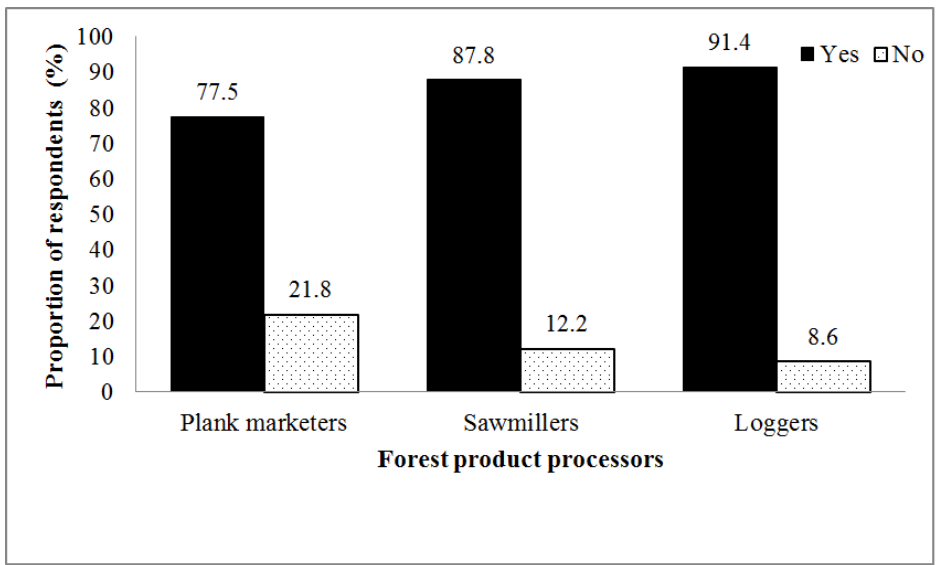

Figure 5. Proportion of timber product processors and plank marketers who sold infected timber products to their customers. 


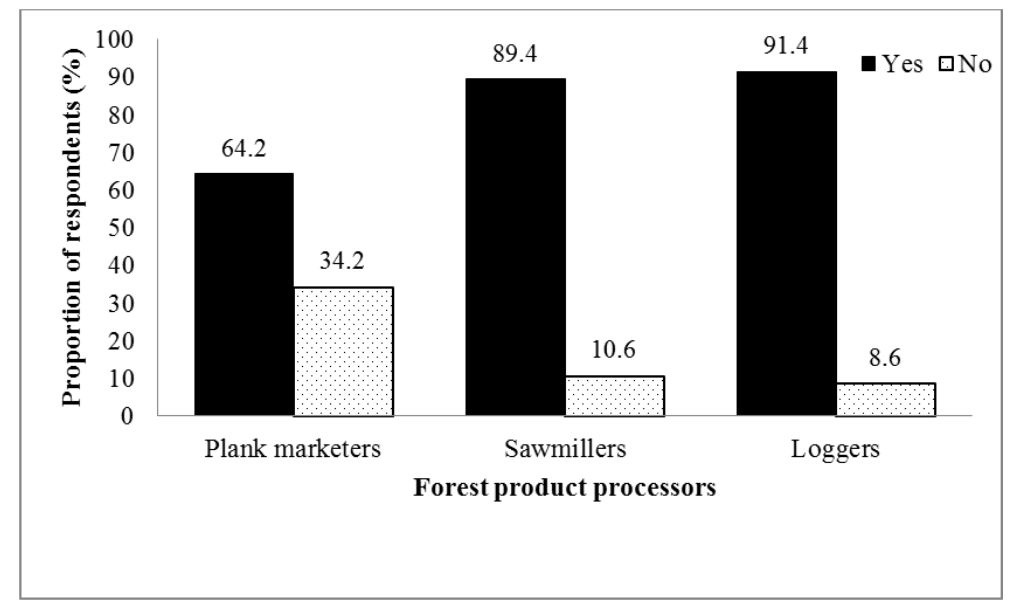

Figure 6. Perception of timber product processors on the negative effect of infested timber products on accruable income.

\subsection{Local Pest Control Measures}

Some methods used for pest control included: chemical and biological treatment, with most respondents not using any treatment (Figure 7). In the plank markets, a commonly used technique was the sorting and separation of infected planks from uninfected ones. In the saw mills, some of the methods used included heat treatment $(2.4 \%)$, irradiation $(0.8 \%)$, fumigation $(25.2 \%)$ and debarking $(34.1 \%)$.

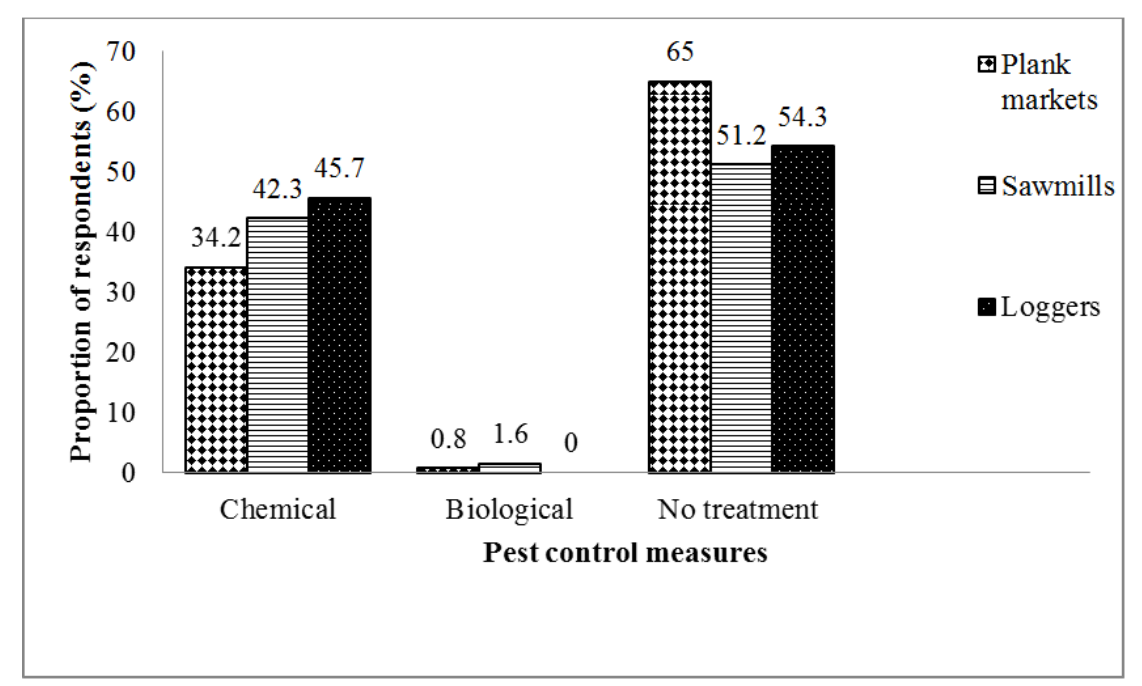

Figure 7. Insect pest control measures used by different timber product processors during timber harvesting, processing, and handling.

\section{Discussion}

\subsection{Awareness on Phytosanitary Measures}

In southwest Nigeria, awareness on the phytosanitary measures required for sustainable timber harvesting and post harvesting operations is low. It was observed that $81.3 \%$ of the saw mill workers had not heard about phytosanitary measures, irrespective of location, gender, educational background, marital status, and years of experience. This corroborates the high rate of pest infestations and damages observed in the saw mills. This low-level of awareness could be partly attributed to the poor dissemination of information from appropriate authorities [4, 8]. A large number of respondents, however, believed that phytosanitary measures were preventive measures that could limit pest infestation in wood products.

\subsection{Institutional Support for Timber Handlers}

The direct movement of pests from the forest into saw mills has been attributed to be the main source of infestation of wood products [4, 10]. Many of the saw mill workers complained about the lack of information from forestry officials, who collect revenue from them and approved the renewal of their saw mill licenses. However, the presence of pests in the harvested logs did not prevent their conversion to planks as it was believed that the processing could help reduce or eliminate some of the pests [10]. Although, sawing exposed the pests to the vagaries of the environment, thus resulting in a temporary initial reduction in their population, eventually, their larvae could cause further infestation on the site resulting in secondary damage at various stages of utilization $[5,6]$. The tree loggers opined that pests were part of the habitats and could not limit their income from the 
forest. It was also discovered that there was no mechanism in place for the transfer of information from the government agencies to tree loggers. Forestry officials are supposed to be the custodians of information that could help in preventing the movement of pests from one place to another, but most of them were not sufficiently aware of phytosanitary measures (Figure 2 and 3) with the exception of quarantine officers, who were experts in the protocols for exportation of forest products from Nigeria, in accordance with International Standards for Phytosanitary Measures [1, 4]. Thus, forestry officials require capacity building to be able to pass this knowledge to stakeholders handling forest products. The logit model revealed that pest infestation records and phytosanitary measures awareness with odd ratios of 0.273 and 13.50 respectively, were the major independent variables that influenced willingness to use phytosanitary measures (Table 3). This implies that stakeholders with pest infestation records and knowledge on phytosanitary measures were most likely going to adopt the measures.

\subsection{Pest Attack on Wood Products}

Pest degradation reduced the quality of the timber products and resulted in high losses of stored planks. The plank marketers sold infested planks at lower prices and some planks were sold as firewood. Plank marketers also complained about the negative effect of these pests on their health with injuries, insect bites, and skin infections, emanating from timber handling. However, tree loggers did not see pest infestation as a major problem probably due to the healthy and diverse nature of the tropical forest $[1,2]$. Pest infestation was prevalent in plank markets, although they could not specifically identify most of the insects. Many of them discovered the infestation without knowing how the insects got into their stores, suggesting that the infestation may be traced to larvae inoculation from the forests $[3,11]$. These infested planks are sold to buyers without any form of treatment. This increases the likelihood of wood failing in service and the insect population being spread to other areas [4]. Nevertheless, these challenges could be tackled with adequate knowledge of pest biology and their interaction with trees and the environment. This will assist in the development of effective pest control strategies, thus minimizing economic losses [11].

\subsection{Treatment and Marketing of Infected Wood Products}

There was no regulatory agency to control chemical use with chemicals such as D-D force, timber guard, solignum and Gamalin 20 being sold in the open market. After sorting, the infested planks are separated from uninfected ones and then chemical treatments are used to prevent further infestation. The infested planks are categorized into different levels such as neat, rough and jacket, depending on the level of damage. The rough ones are sold as firewood, resulting in losses to the marketers and the movement of particular pests into new environments. The method used by the tree loggers in the forest site included fumigation, while $40.0 \%$ did not embark on any form of treatment. In addition, there were no precautionary measures to reduce further spread as logs with or without pests are loaded together in trucks and transported from the forest site into the saw mills. There is, therefore, need for monitoring and surveillance programs in order to curb the spread of forest pests [12]. Many abandoned logs in the saw mills that could have been used for furniture and construction work are usually destroyed by insect pests; however with proper management, losses could be drastically reduced $[2,13]$.

\section{Conclusion}

Phytosanitary measures enhance timber processing and utilization, while controlling pest movement and infestation. However, it was observed that little was being done to utilize these measures in the harvesting, processing, and handling of timber in southwest Nigeria. Hence, insect pest damage to timber products caused high economic losses to plank marketers, saw mill workers and tree loggers. It also reduced the quality and quantity of timber products obtained from felled trees. Therefore, it is pertinent to create awareness on the benefits of using phytosanitary measures in order to reduce pest damage to timber products. This would also increase the potential opportunities available for expansion of the timber industry in southwest Nigeria.

\section{Acknowledgements}

We are grateful to Dr. Akintunde A. Alo of the GIS and Remote Sensing Unit, Department of Social and Environmental Forestry, University of Ibadan, Ibadan Nigeria, for providing assistance during the preparation of the manuscript. In addition, we appreciate the reviewers for making constructive suggestions during the review process.

\section{References}

[1] ISPM, 2010. International Standards for Phytosanitary Measures No. 05. Glossary of phytosanitary terms. Food and Agriculture Organization, 1-27.

[2] Rosenberger, R. S. and Smith, E. L., 1997. Nonmarket economic impacts of forest insect pests: a literature review. General Technical Report, PSW-GTR-164-ww. Pacific Press, Albany, Canada.

[3] Beal, R. H., 1981. Termite control studies in Panama. US Department of Agriculture, Forestry Service and Resources, 50-56.

[4] FAO, 2011. Guide to implementation of phytosanitary standards in forestry. Forestry Paper No. 164, Food and Agriculture Organization, 28-30.

[5] Ciesla, W. M., 2001. Protecting plantations from pests and diseases. Forest Plantation Thematic Papers, Forest Resources Division. Food and Agriculture Organization, Rome, 10.

[6] Nair, K. S. S., 2007. Tropical forest insect pests: ecology, impact, and management. Cambridge University Press, 105-118. 
[7] Averill, R. D. Larson, L., Saveland, J. Wargo, P. Williams, J. and Bellinger, M., 1995. Disturbance processes and ecosystem management. Forest Service, U. S. Department of Agriculture, Washington, DC., 13.

[8] Griffiths, M., Wylie, R., Lawson, S., Pegg, G. and McDonald, J., 2004. Known or potential threats from pests and diseases to prospective tree species for high-value timber plantings in northern Australia. In: Bevege, D. I. (ed.), Prospects for highvalue hardwood timber plantations in the 'dry' tropics of northern Australia, Private Forestry, Queensland, Mareeba, Northern Australia.

[9] Haack, R. A., Petrice, T. R., Wiedenhoeft, A. C., 2010. Incidence of bark and wood boring insect in fire woods: A survey at Michigan's Mackinac Bridge. Journal of Economic Entomology 103: 1683-1692.
[10] Ren, Y., Brien G. O., and Desmarchelier J. M., 1997. Improved methodology for studying diffusion, sorption and desorption in timber fumigation. Journal of Stored Product Resources 33: 199-208.

[11] Douce, G. K., Moorhead, D. J., and Bargeron, C. T., 2002. Forest pest control. The University of Georgia, College of Agricultural and Environmental Sciences, Special Bulletin 16.

[12] Basavaraju B. S, Chakravarthy, A. K, Doddabasappa, B., Nagachaitanya. B., and Yathish K. R., 2010. Threats to natural resources by insect invasives. Karnataka Journal of Agricultural Science 23: 1-5.

[13] Robert, O. O. (2012). Preservation of forest trees against pests and insects attack. Nigeria International Journal of Modern Botany, 2 (4): 92-96. 